\title{
Visual performance of the Tecnis one-piece lens ZCB00
}

This article was published in the following Dove Press journal:

Clinical Ophthalmology

22 December 2011

Number of times this article has been viewed

\section{Sherein S Wahba \\ Riad F Riad \\ Fathy F Morkos \\ Abdallah K Hassouna \\ Maged M Roshdy}

National Eye Hospital and Ain Shams University, Cairo, Egypt
Correspondence: Sherein Shafik Wahba 6 Mohamed Shokry Street, Gesr El Suez, Al Zaitoun, Cairo, Egypt

Tel +2 01222421896

Email s_shafik@hotmail.com
Synopsis: The aspheric, one-piece design of the Tecnis ${ }^{\circledR}$ ZCB00 intraocular lens provided higher mesopic contrast sensitivity and relatively constant refraction at different pupil sizes compared to the Sensar ${ }^{\circledR}$ AR40e.

Purpose: Comparing the impact on functional vision of the aspheric Tecnis ${ }^{\circledR} \mathrm{ZCB} 00$ one-piece lens compared to the spherical Sensar ${ }^{\circledR}$ AR40e three-piece lens.

Setting: National Eye Hospital, Cairo, Egypt.

Methods: In this prospective study, we implanted 32 Tecnis ZCB00 (Abbott Medical Optics, Santa Ana, CA) and 30 Sensar AR40e (Pharamacia and Upjohn LLC, North Peapack, NJ) lenses. Twenty-three patients in the ZCB00 group and 13 patients in the AR40e group provided reliable, reproducible data, and were therefore included in the statistical analysis. After 8 weeks, we measured photopic contrast sensitivity (PCS) at $85 \mathrm{~cd} / \mathrm{m}^{2}$ and mesopic contrast sensitivity (MCS) at $5 \mathrm{~cd} / \mathrm{m}^{2}$. Uncorrected and best-corrected visual acuity were measured. Myopic shift was analyzed by comparing the manifest refraction spherical equivalent at 3 days and 8 weeks after surgery in the normal and dilated pupil.

Results: The Tecnis ZCB00 group showed significantly better MCS than the Sensar AR40e group at a spatial frequency of six cycles per degree (cpd) $(P=0.037)$, but not at 3,12 , or 18 cpd $(P=0.299, P=0.226$, and $P=0.396$, respectively). There were no significant differences between groups in corrected distance visual acuity $(P=0.175)$ or PCS at $3,6,12$, or 18 cpd spatial frequencies ( $P=0.440, P=0.176, P=0.365$, and $P=0.251$, respectively). The ZCB00 group showed less myopic shift in normal and dilated pupils between 3 days and 8 weeks after surgery compared to the AR40e group, but this difference was not significant.

Conclusion: The Tecnis one-piece ZCB00 provided higher MCS at moderate spatial frequency than the three-piece Sensar AR40e, and was associated with relatively constant refraction at different pupil sizes.

Keywords: Tecnis ZCB00, Sensar AR40e, contrast sensitivity, myopic shift

\section{Introduction}

The decreases in visual acuity and contrast sensitivity that occur with age are usually attributed to changes in the lens. ${ }^{1}$ The crystalline lens undergoes positive spherical aberration (SA) with age, which disrupts the wave front balance with the cornea and increases the positive SA of the whole eye. ${ }^{2}$ In young subjects, the crystalline lens compensates for any positive SA in the cornea with negative SA, which results in a low level of SA for the entire eye. ${ }^{3}$ Traditional intraocular lenses (IOLs) also have positive SA, and therefore, they produce a pseudophakic eye that is no better than an aged eye with a transparent lens in this regard. ${ }^{4}$ 
Aspheric IOLs are designed to introduce optical path differences that bend the light rays to a single focus on the retina. There are several IOL designs that compensate for the SA by making one or both surfaces aspheric. ${ }^{5}$

Several studies ${ }^{6-10}$ have suggested that implantation of these aspheric IOLs might improve contrast sensitivity and enhance patient quality of life. However, others ${ }^{11}$ found no significant differences in contrast sensitivity between aspheric and spherical IOLs.

In this study, we compared the performance of the Tecnis $^{\circledR}$ ZCB00 (Abbott Medical Optics, Santa Ana, CA) and Sensar ${ }^{\circledR}$ AR40e (Pharamacia and Upjohn LLC, North Peapack, NJ) with regard to their contribution to visual outcome and contrast sensitivity. Tecnis ZCB00 is a one-piece $6.0 \mathrm{~mm}$ biconvex hydrophobic acrylic lens with anterior aspheric surface that resulted in a negative SA of $-0.27 \mu \mathrm{m}$ and frosted continuous $360^{\circ}$ posterior square edge. Sensar AR40e is a three-piece $6 \mathrm{~mm}$ biconvex spheric hydrophobic acrylic lens with OptiEdge ${ }^{\mathrm{TM}}$ (Abbott Medical Optics) design and polymethylmethacrylate (PMMA) haptic with $5^{\circ}$ angulation (Table 1).

\section{Patients and methods}

A randomized prospective study was conducted in 62 eyes in patients that required cataract surgery at the National Eye Hospital. Exclusion criteria included ocular surface pathology, uncontrolled glaucoma, existing retinal or optic disc pathology, and systemic diseases that could potentially affect the vision, like diabetes. After cataract removal, the patients were divided into two groups. The first group of 32 eyes received implants of aspheric Tecnis ZCB00 lenses (Abbott Medical Optics) and the second group of 30 eyes received implants of spherical Sensar AR40e lenses (Abbott Medical Optics). Informed consent was obtained from all participants and the study was reviewed by the National Eye Hospital ethics committee.

Table I Features of the two IOL types used in this study

\begin{tabular}{ll}
\hline Tecnis $^{\circledR}$ ZCB00 & Sensar $^{\circledR}$ AR40e \\
\hline One-piece IOL & Three-piece IOL \\
6.0-mm biconvex, anterior aspheric & 6-mm biconvex spheric \\
surface, square optic edge & hydrophobic acrylic optic \\
Frosted continuous $360^{\circ}$ posterior & OptiEdge ${ }^{\circledR}$ design \\
square edge & \\
Haptic offset from optic & $5^{\circ}$ haptic angulation \\
UV blocking hydrophobic acrylic haptic & PMMA haptic \\
I3 mm D, RI: I.47 & I3 mm D, RI: I.47 \\
\hline
\end{tabular}

Abbreviations: IOL, intraocular lens; PMMA, polymethylmethacrylate; D, diameter; $\mathrm{RI}$, refractive index.

\section{Surgical procedure}

All surgical procedures were performed with the same technique, and the same phaco machine. After administration of periocular anesthesia, a corneal incision of $2.4 \mathrm{~mm}$ was performed in the steep meridian when possible, a $5-\mathrm{mm}$ continuous capsulorhexis was performed, followed by phacoemulsification cataract extraction. Next, an IOL was implanted with an injector; then, the IOL was centered and the meticulous ophthalmic viscoelastic device was washed.

\section{Evaluation}

All patients had a full preoperative ocular examination, including refraction testing, best corrected distance visual acuity (CDVA) testing, tonometry, funduscopy, slit-lamp examination, and corneal topography. Patients were examined directly after surgery for the baseline data; then, again, at 2-3 days, 2 weeks, and 6-8 weeks after surgery. The data presented included refraction, CDVA (recorded in logarithm of minimum angle of resolution [logMAR]), corneal topography, photopic contrast sensitivity (PCS), and mesopic contrast sensitivity (MCS).

Contrast sensitivity was measured with the CSV1000E test (Good-Lite, Elgin, IL), using sine-wave grating charts to measure spatial frequencies of $3,6,12$, and 18 cycles per degree (cpd). The CSV1000E test has been used in several studies and has been shown to give reliable, repeatable contrast sensitivity function scores. ${ }^{12}$ All measurements were performed under photopic conditions at $85 \mathrm{~cd} / \mathrm{m}^{2}$ and under mesopic conditions at $5 \mathrm{~cd} / \mathrm{m}^{2}$.

According to Wachler and Krueger ${ }^{13}$ contrast sensitivity values were normalized using the ratio between a patient's result and the normal score for the patient's age group. Scores higher or lower than 1.0 indicated contrast sensitivities higher or lower than expected.

Corneal topography was measured with a WaveLight ${ }^{\circledR}$ Allegro Oculyzer with software version 1.16r12 (WAVELIGHT AG, Erlangen, Germany) to ensure corneal regularity.

\section{Statistical analysis}

Data were collected, verified, and the changes were calculated with Microsoft Excel 2007. Statistical analyses were performed with MedCalc (v 11.1.1.0, MedCalc Software,

Table 2 Study group demographics and IOL information

\begin{tabular}{llll}
\hline & Tecnis $^{\circledR}$ ZCB00 & Sensar $^{\circledR}$ AR40e & P value \\
\hline Mean age (year) \pm SD & $63.6 \pm 8.0$ & $61.6 \pm 12.7$ & 0.354 \\
Male/female & $8 / 15$ & $4 / 9$ & 0.065 \\
Right/Left & $13 / 10$ & $7 / 6$ & 0.846 \\
\hline
\end{tabular}

Abbreviations: IOL, intraocular lens; SD, standard deviation. 
Table 3 Myopic shifts at different pupil sizes and mean IOL powers in the two study groups

\begin{tabular}{|c|c|c|c|c|c|c|}
\hline & \multicolumn{2}{|c|}{ Myopic shift, undilated pupil } & \multicolumn{2}{|c|}{ Myopic shift, dilated pupil } & \multicolumn{2}{|c|}{ Mean IOL power (diopter) } \\
\hline & $\begin{array}{l}\text { Mean } \pm \text { SD } \\
\text { (diopter) }\end{array}$ & $P$ value & $\begin{array}{l}\text { Mean } \pm \text { SD } \\
\text { (diopter) }\end{array}$ & $P$ value & $\begin{array}{l}\text { Mean } \pm \text { SD } \\
\text { (diopter) }\end{array}$ & $P$ value \\
\hline Tecnis $^{\circledR}$ ZCB00 & $-0.06 \pm 0.59$ & 0.194 & $0.06 \pm 0.48$ & 0.196 & $19.1 \pm 5.9$ & 0.19 \\
\hline Sensar ${ }^{\circledast}$ AR40e & $-0.32 \pm 0.45$ & & $-0.16 \pm 0.36$ & & $18.7 \pm 6.3$ & \\
\hline
\end{tabular}

Abbreviations: IOL, intraocular lens; SD, standard deviation.

Mariakerke, Belgium). The following tests were performed: calculation of the mean, standard deviation (SD), the $t$-test for independent samples of parametric data with equal variances, and the Welch test for independent samples of parametric data with unequal variances.

\section{Results}

Twenty-three patients in the Tecnis ZCB00 group and 13 patients in the SensarAR40e group attended all the follow-up visits in the study. Their data were reliable and reproducible (no same visit variability); therefore, all were included in the statistical analysis.

\section{Patients}

The mean age of the patients was $63.8 \pm 10.4$ years. The male to female ratio was 23:39. The right to left ratio was 20:16. The demographic characteristics of the study groups are reported in Table 2. The mean IOL power was $19.3 \pm 5.3$ in the Tecnis ZCB00 group, and $17.3 \pm 6.3$ in the Sensar AR40e group $(P=0.194)$ (Table 3$)$.

\section{Visual acuity}

Two months post-operatively, the mean CDVA was $0.89 \pm 0.17$ in the Tecnis ZCB00 group, and $0.96 \pm 0.14$ in the Sensar AR40e group, with no significant difference between groups $(P=0.175)$ (Figure 1).

\section{Contrast sensitivity}

The Tecnis ZCB00 one-piece showed better PCS than the Sensar AR40e three-piece at all spatial frequencies (Figure 2, Table 4),

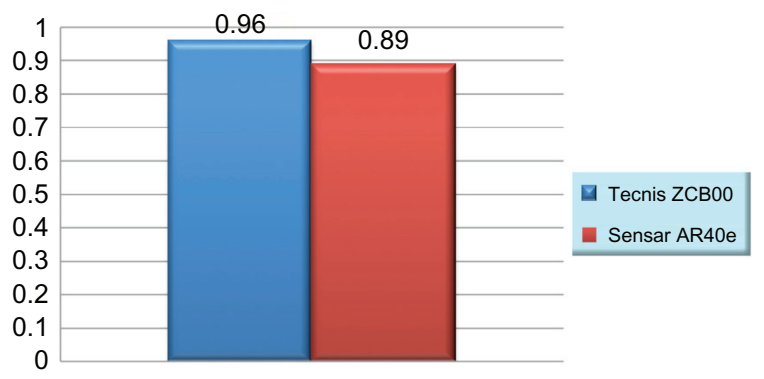

Figure I A comparison of mean best-corrected visual acuities measured at 2 months post-operatively. but there were no statistically significant differences between groups $(P=0.440, P=0.176, P=0.365$, and $P=0.251$, respectively).

At a spatial frequency of $6 \mathrm{cpd}$, the MCS was significantly better in the Tecnis ZCB00 one-piece group than in the SensarAR40e three-piece group $(P=0.037$; Figure 3, Table 5); however, at spatial frequencies of 3,12, or $18 \mathrm{cpd}$, the MCS was not significantly different between the two groups ( $P=0.299, P=0.226$, and $P=0.396$, respectively).

\section{Myopic shift}

In undilated eyes, the change in spherical equivalent from 3 days to 2 months was lower in the Tecnis ZCB00 lenses $(-0.06 \mathrm{D})$ than in Sensar AR40e lenses $(-0.32 \mathrm{D})$, but this difference was not statistically significant $(P=0.194$; Table 3$)$. In dilated eyes, the change in spherical equivalent from 3 days to 2 months was lower in the Tecnis ZCB00 lenses $(0.06 \mathrm{D})$ than in the Sensar AR40e lenses $(-0.16 \mathrm{D})$, but this difference was not statistically significant $(P=0.196$; Table 3$)$. This indicated that there was less myopic shift with the Tecnis ZCB00 one-piece lenses than with the Sensar AR40e threepiece lenses in both dilated and undilated eyes.

\section{Discussion}

Optical aberrations during cataract surgery can be reduced by implanting aspheric IOL. Standard IOLs add positive SA to that already induced by the cornea and, thereby, they decrease optical quality. The goal of the current study was to evaluate the visual performance of aspheric Tecnis ZCB00 one-piece hydrophobic acrylic lenses and compare them to spherical Sensar AR40e three-piece hydrophobic acrylic lenses.

In this study, we found no significant difference between groups in the post-operative CDVA $(P=0.175)$. In contrast, Bellucci et $a{ }^{10}{ }^{10}$ compared the CDVA (logMAR) in patients that received implants of Tecnis Z9000 or conventional AcrySof SA60AT IOL. They reported a difference of approximately three letters in favor of the Tecnis Z9000 IOL implants. On the other hand, Thiagarajan et $\mathrm{al}^{14}$ found a statistically significant difference in CDVA but not 


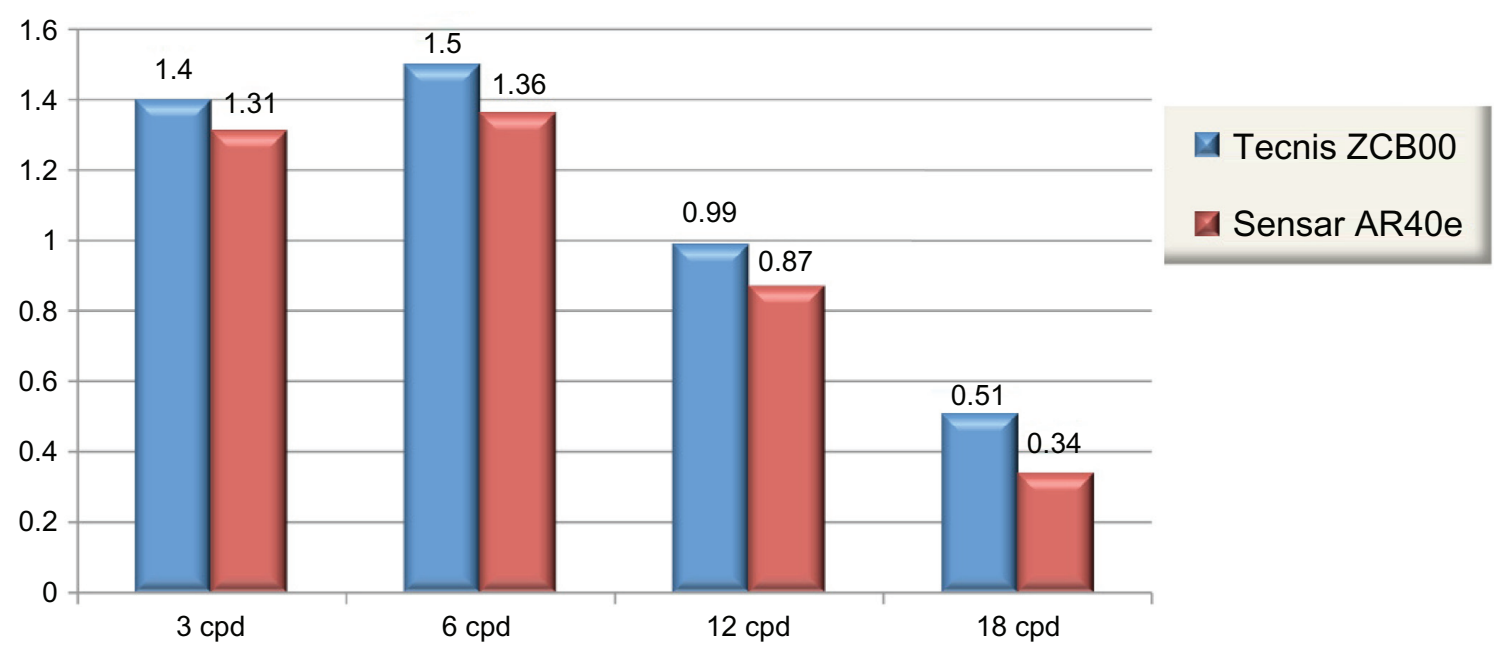

Figure 2 Mean photopic contrast sensitivities of the two study groups.

clinically important (relative difference $1.5 \%$ ), between Akreos Adapt Advanced Optics (AO) (Bausch and Lomb, Inc, Rochester, NY) aspheric intraocular lens (IOL) and the Sensar AR40e spherical acrylic IOL, in favor of the spherical IOL.

In a study by Munoz et $\mathrm{al}^{2}$, there were no statistically significant differences in CDVA among patients that received implants of aspheric Tecnis Z9000 IOL, the AR40e IOL, or the Stabibag (Carl Zeiss Meditec, Inc, Dublin, CA) IOLs. Pandita et $\mathrm{a}^{15}$ evaluated the CDVA in patients that had implants of AcrySof SA60AT, AcrySof Natural SN60AT, or AcrySof IQ SN60WF IOLs; the results were similar among the three groups. Also, Morales et a ${ }^{16}$ compared visual acuity in patients who had a spherical IOL (SoFlex SE, Bausch and Lomb) implanted in one eye and an aspheric IOL (SofPort $\mathrm{AO}$, Bausch and Lomb) implanted in the fellow eye and there were no statistical differences among the two groups. Thus, the previous studies showed results similar to our results for the CDVA.

In the current study, we found no significant differences in the PCS between the Tecnis ZCB00 Aspheric IOL and the Sensar AR40e spherical IOL at all spatial frequencies. However, at $6 \mathrm{cpd}$, the MCS in the Tecnis ZCB00 was significantly better than that in the Sensar AR40e.

Table 4 Mean photopic contrast sensitivities of the two study groups

\begin{tabular}{lllll}
\hline $\begin{array}{l}\text { Photobic contrast } \\
\text { sensitivity (mean) }\end{array}$ & 3 cpd & 6 cpd & 1 2 cpd & 18 cpd \\
\hline Tecnis $^{\circledR}$ ZCB00 & 1.4 & 1.5 & 0.99 & 0.5 I \\
Sensar $^{\circledR}$ AR40e & 1.31 & 1.36 & 0.87 & 0.34 \\
\hline
\end{tabular}

Abbreviation: cpd, cycles per degree.
Our results were comparable to those from the study by Denoyer et $\mathrm{al}^{17}$ who compared aspheric Tecnis Z9000 and spherical CeeOn ${ }^{\mathrm{TM}}$ Edge 911 (Pharmacia, Kalamazoo, MI) IOLs. That study revealed that the Tecnis Z9000 group showed significantly better MCS at high spatial frequencies; however, the contrast sensitivity under photopic and glare conditions did not differ between the two groups. Also, the study by Morales et $\mathrm{al}^{16}$ was comparable to our results; their study compared aspheric SofPort $\mathrm{AO}^{\circledR} \mathrm{IOL}$ (Bausch and Lomb) and spherical SoFlex SE ${ }^{\circledR}$ IOL (Bausch and Lomb). They found no statistical difference between groups under photopic conditions but better performance was observed with the aspheric IOL at low spatial frequencies under mesopic conditions.

Ohtani et a $\mathrm{l}^{18}$ found no significant differences in contrast sensitivity, under either photopic or mesopic conditions, between patients that received implants of Tecnis Z9003 IOLs or the AR40e. Munoz et $\mathrm{al}^{2}$ found that both the PCS and MCS were similar in patients that received implants of Tecnis Z9000, Sensar AR40e, or Stabibag IOLs. Also, Thiagarajan et $\mathrm{al}^{14}$ found no statistically significant differences in contrast sensitivity between Akreos Adapt Advanced Optics aspheric intraocular lens (IOL) and the Sensar AR40e spherical acrylic IOL.

However, our results contrasted with those of Pandita et al. ${ }^{15}$ They found that, compared to the AcrySof SA60AT and AcrySof SN60AT, the AcrySof IQ IOLs provided significantly higher PCS at $18 \mathrm{cpd}$, higher MCS with a $4.0 \mathrm{~mm}$ aperture at all spatial frequencies without glare and with glare, and higher MCS with a $6.0 \mathrm{~mm}$ aperture at all spatial frequencies without glare and with glare. Also, Bellucci et al ${ }^{10}$ showed that, compared to AcrySof SA60AT IOLs, the Tecnis 


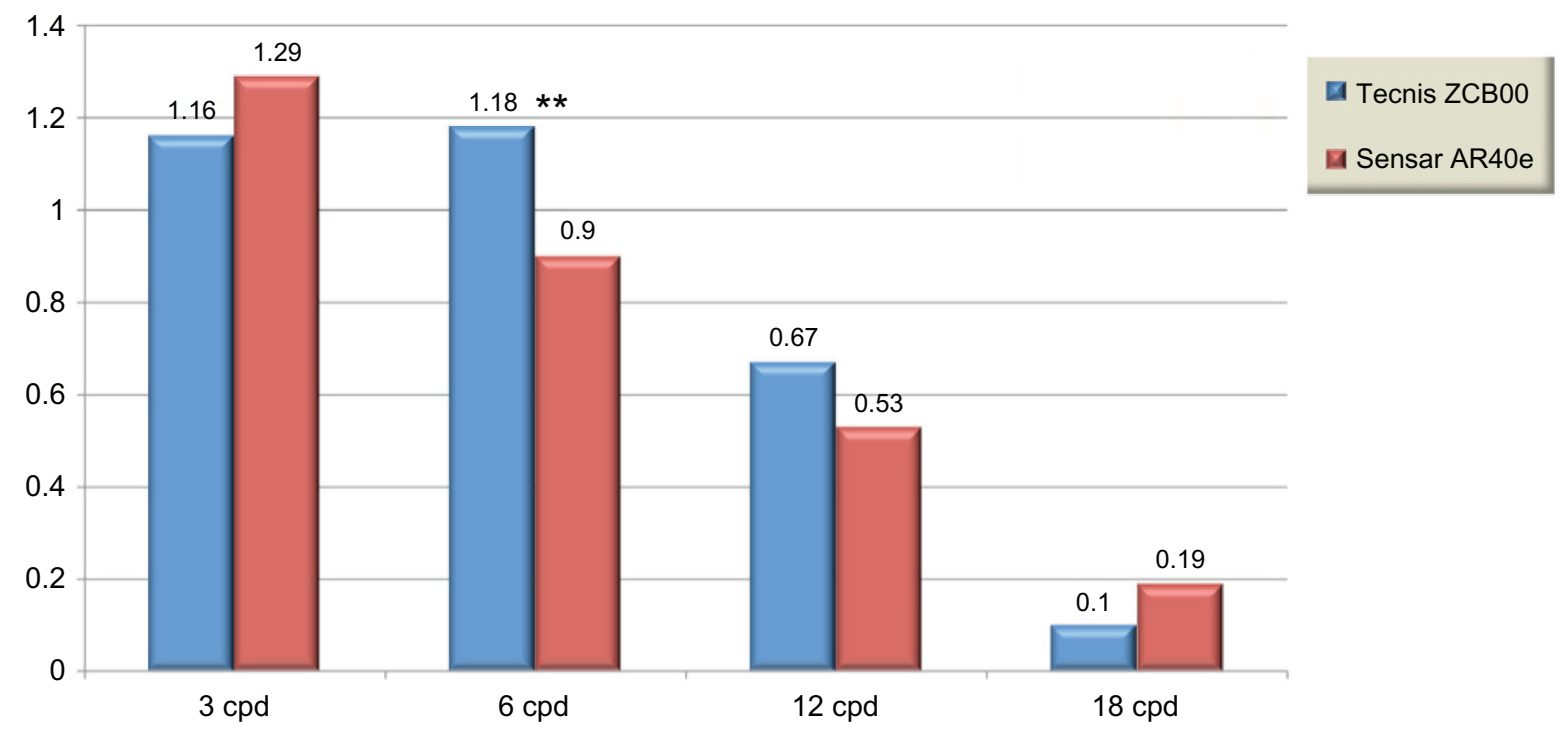

Figure 3 Mean mesopic contrast sensitivities of the two study groups. Note: $* * P<0.05$.

Z9000 IOLs provided better contrast sensitivity at 3, 6, 12, and $18 \mathrm{cpd}$ in both photopic and mesopic conditions, with a peak improvement at $18 \mathrm{cpd}$.

There are several possible explanations for the lack of significant differences in visual performance among different IOLs. First, both IOLs used in our study were made of the same hydrophobic acrylic material. Second, the aspheric nature of the Tecnis one-piece ZCB00 will improve the SA of the eye, but this effect will mainly appear in mesopic conditions, as was the case in our study. Third, an improvement in the optical quality of the eye may not necessarily lead to an improvement in the quality of vision.

In the current study, there was less myopic shift with the Tecnis ZCB00 than with the Sensar AR40e in different pupil sizes, but this difference was not statistically significant. Our results were comparable to those of Bellucci et $\mathrm{al}^{19}$ who found that, in contrast to the myopic shift that tends to occur with the implantation of a spherical IOL, no shift occurred when they implanted the Tecnis one-piece IOL.

Nejima et $\mathrm{al}^{20}$ found that, although the MA60AC threepiece IOL showed significant forward shift and myopic

Table 5 Mean mesopic contrast sensitivities of the two study groups

\begin{tabular}{lllll}
\hline $\begin{array}{l}\text { Mesopic contrast } \\
\text { sensitivity (mean) }\end{array}$ & 3 cpd & $\mathbf{6}$ cpd & I 2 cpd & I 8 cpd \\
\hline Tecnis $^{\circledR}$ ZCB00 & 1.16 & 1.18 & 0.67 & 0.1 \\
Sensar $^{\circledR}$ AR40e & 1.29 & 0.9 & 0.53 & 0.19 \\
\hline
\end{tabular}

Abbreviation: cpd, cycles per degree. refractive changes after surgery, the SA60AT one-piece IOL displayed little axial movement and was associated with highly stable refraction after surgery. Szurman et al ${ }^{21}$ evaluated the aspheric design of the Tecnis one-piece and how it correlated to patient benefits in 102 patients; they found no myopic shifts at larger diameters. Petermeier et $\mathrm{al}^{22}$ evaluated the influence of the pupil size on clinical results and objective parameters of optical quality of the Tecnis one-piece (ZCB00) IOLs. His study included 51 eyes; they found the defocus curves with a $3-\mathrm{mm}$ and a $5-\mathrm{mm}$ pinhole were not statistically significantly different, which was comparable to our results. Taken together, these results suggested that the one-piece design conferred more stable refraction at different pupil sizes.

In conclusion, we found that the aspheric property of the Tecnis one-piece ZCB00 IOL provided higher MCS at moderate spatial frequency than the spherical three-piece Sensar AR40e. Furthermore, its one-piece property was associated with a relatively constant refraction at different pupil sizes. In the future, a meta-analysis might provide conclusive evidence that could confirm or negate the real benefit of one IOL model compared to the others.

\section{Disclosure}

Sherein S Wahba and Maged M Roshdy received travel support from Abbott Medical Optics, Inc, Santa Ana, CA. Riad F Riad, Fathy F Morkos and Abdallah K Hassouna received travel support and equipment from Abbott Medical Optics, Inc, Santa Ana, CA and Alcon Laboratories, Inc, CA. The authors have no other financial interest in the products 
mentioned in this paper. This paper was presented at the XXVIII Congress of the ESCRS, Paris, France, September 4-8, 2010.

\section{References}

1. Owsley C, Sekuler R, Siemsen D. Contrast sensitivity throughout adulthood. Vision Res. 1983;23(7):689-699.

2. Muñoz G, Albarrán-Diego C, Montés-Mico R, Rodríguez-Galietero A, Alió JL. Spherical aberration and contrast sensitivity after cataract surgery with the Tecnis Z9000 intraocular lens. J Cataract Refract Surg. 2006;32(8):1320-1327.

3. Artal P, Berrio E, Guirao A, Piers P. Contribution of the cornea and internal surfaces to the changes of ocular aberrations with age. $J O p t$ Soc Am A Opt Image Sci Vis. 2002;19(1):137-143.

4. Atchison DA. Design of aspheric intraocular lenses. Ophthalmic Physiol Opt. 1991;11(2):137-146.

5. Franchini A. Compromise between spherical and chromatic aberration and depth of focus in aspheric intraocular lenses. $J$ Cataract Refract Surg. 2007;33(3):497-509.

6. Packer M, Fine IH, Hoffman RS, Piers PA. Prospective randomized trial of an anterior surface modified prolate intraocular lens. $J$ Refract Surg. 2002;18(6):692-696.

7. Mester U, Dillinger P, Anterist N. Impact of a modified optic design on visual function: clinical comparative study. $J$ Cataract Refract Surg. 2003;29(4):652-660.

8. Kershner RM. Retinal image contrast and functional visual performance with aspheric, silicone, and acrylic intraocular lenses. Prospective evaluation. J Cataract Refract Surg. 2003;29(9): 1684-1694.

9. Packer M, Fine IH, Hoffman RS, Piers PA. Improved functional vision with a modified prolate intraocular lens. J Cataract Refract Surg. 2004;30(5):986-992.

10. Bellucci R, Scialdone A, Buratto L, et al. Visual acuity and contrast sensitivity comparison between Tecnis and AcrySof SA60AT intraocular lenses: A multicenter randomized study. J Cataract Refract Surg. 2005;31(4):712-717; Erratum in: J Cataract Refract Surg. 2005;31(10):1857.
11. Kasper T, Bühren J, Kohnen T. Visual performance of aspherical and spherical intraocular lenses: intraindividual comparison of visual acuity, contrast sensitivity, and higher-order aberrations. J Cataract Refract Surg. 2006;32(12):2022-2029.

12. Quesnel NM, Lovasik JV, Ferremi C, Boileau M, Ieraci C. Laser in situ keratomileusis for myopia and the contrast sensitivity function. J Cataract Refract Surg. 2004;30:1209-1218.

13. Wachler BS, Krueger RR. Normalized contrast sensitivity values. $J$ Refract Surg. 1998;14(4):463-466.

14. Thiagarajan M, McClenaghan R, Anderson DF. Comparison of visual performance with an aspheric intraocular lens and a spherical intraocular lens. J Cataract Refract Surg. 2011;37(11):1993-2000.

15. Pandita D, Raj SM, Vasavada VA, Vasavada VA, Kazi NS, Vasavada AR. Contrast sensitivity and glare disability after implantation of AcrySof IQ Natural aspherical intraocular lens: prospective randomized masked clinical trial. J Cataract Refract Surg. 2007;33(4):603-610.

16. Morales EL, Rocha KM, Chalita MR, Nosé W, Avila MP. Comparison of optical aberrations and contrast sensitivity between aspheric and spherical intraocular lenses. J Refract Surg. 2011;27(10):723-728.

17. Denoyer A, Le Lez ML, Majzoub S, Pisella PJ. Quality of vision after cataract surgery after Tecnis Z9000 intraocular lens implantation: effect of contrast sensitivity and wavefront aberration improvements on the quality of daily vision. J Cataract Refract Surg. 2007;33(2):210-216.

18. Ohtani S, Miyata K, Samejima T, Honbou M, Oshika T. Intraindividual Comparison of Aspherical and Spherical Intraocular Lenses of Same Material and Platform. Ophthalmology. 2009;116:896-901.

19. Bellucci R, Morselli S, Piers P. Comparison of wavefront aberrations and optical quality of eyes implanted with five different intraocular lenses. J Refract Surg. 2004;20(4):297-306.

20. Nejima R, Miyai T, Kataoka Y, et al. Prospective intrapatient comparison of 6.0-millimeter optic single-piece and 3-piece hydrophobic acrylic foldable intraocular lenses. Ophthalmology. 2006;113(4):585-590.

21. Szurman P, Petermeier K. Aspheric IOLs benefit quality of vision. Clinical results after Tecnis 1-Piece IOL implantation are promising. Cataract \& Refractive Surgery Today Europe. 2009:17-18.

22. Petermeier K, Frank C, Gekeler F, Spitzer MS, Messias A, Szurman P. Influence of the pupil size on visual quality and spherical aberration after implantation of the Tecnis 1-piece intraocular lens. Br J Ophthalmol. 2011;95(1):42-45.
Clinical Ophthalmology

\section{Publish your work in this journal}

Clinical Ophthalmology is an international, peer-reviewed journal covering all subspecialties within ophthalmology. Key topics include: Optometry; Visual science; Pharmacology and drug therapy in eye diseases; Basic Sciences; Primary and Secondary eye care; Patient Safety and Quality of Care Improvements. This journal is indexed on Submit your manuscript here: http://www.dovepress.com/clinical-ophthalmology-journal

\section{Dovepress}

PubMed Central and CAS, and is the official journal of The Society of Clinical Ophthalmology (SCO). The manuscript management system is completely online and includes a very quick and fair peer-review system, which is all easy to use. Visit http://www.dovepress.com/ testimonials.php to read real quotes from published authors. 